\title{
What's in a Name? Using Card Sorting to Evaluate Branding in an Academic Library's Web Site
}

\author{
Peter Hepburn and Krystal M. Lewis
}

\begin{abstract}
Libraries are pressed to effectively promote use of the tools they provide users as well as their role in creating, selecting, and purchasing them. Applying "brand names" generated within the library is one promotional strategy. Usability testing at one academic library demonstrated how the card sorting technique can be used to evaluate branding efforts. The study found that library users do not recognize or comprehend library brand names in the absence of a consistent approach to branding even if they do use the services that have been branded.
\end{abstract}

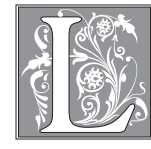

ibraries are pressed to demonstrate their worth, both to their parent organization (the college or university) and to their users. Librarians frequently observe that users are accustomed to relying on Internet resources found through freely available search engines such as Google or Yahoo. As a result, users do not often understand that the various electronic subscriptions to scholarly materials that they use have been vetted by the library, are generally more reliable, and are paid for through the library's budget, or that the library offers services to obtain scholarly materials they do not own. The library provides access to excellent scholarly material, but users are often unaware of these resources. To promote the use of the resources and services they provide-and to establish the library's role in the development, selection, and provision of them-libraries will name or "brand" their resources and services. For example, a database will be known as X Library's Database Y or something similar. The library's Web site then must balance the seamless provision of such resources and services with the library's desire to underscore its role in creating, choosing, and offering them. Evaluating the presentation of resources and services through library Web sites has been the subject of a number of usability tests in past years. While Web site usability tests usually uncover a host of information about the placement of links, color schemes, and site architecture, testing can also measure responses to library branding efforts.

Peter Hepburn is Digitization Librarian and Assistant Professor in the Richard J. Daley Library at the University of Illinois at Chicago; e-mail: phepburn@uic.edu. Krystal M. Lewis is Assistant Reference Librarian and Assistant Professor in the Richard J. Daley Library at the University of Illinois at Chicago; e-mail:kmlewis1@uic.edu. The authors thank Francis Kayiwa for his contributions as one-third of the card sort test team. They are grateful to Lisa Wallis for her contributions to the process and to the UIC Library's Web Oversight Committee for their support of the undertaking. They wish to thank Ann C. Weller and John M. Cullars for their considerate comments and suggestions. 


\section{Literature}

Published results from a number of usability studies have measured the efficacy and appeal of library Web pages. Usability studies are generally well known in libraries including UIC, ${ }^{1,2}$ but the card sort technique is not common. Card sorting is a method in which subjects sort index cards labeled with Web site content into groupings that make sense to them. An examination of the library science literature for models of this technique uncovered four major studies. In 1999, after running a task-oriented usability study of their site, the MIT Libraries conducted a card sorting study of Web site content. ${ }^{3}$ This was followed by a category description survey and a "reverse category survey" in which users were asked which of five categories they would choose first to find a specific item from the Web site. The results of the card sort and surveys were used to group and (to some extent) label content according to the user's perspective in the redesigned Web site. Cornell University was also an early adopter among academic libraries of the card sorting technique. The Faiks and Hyland study at Cornell was confined to a section of the Cornell Library Web site, the Gateway Help, not the whole site. Moreover, the Cornell study was less concerned with terminology specifically than with organization of help topics. ${ }^{4}$ In a study at SUNY-Buffalo (now the University at Buffalo), participants grouped tasks commonly performed using the library's Web site. The study focused almost exclusively on site nomenclature, though not so far as branding might be involved. ${ }^{5} \mathrm{~A}$ University of Arizona study underscored some of the guidance the MIT and Cornell studies offered, but neither it nor the rest of the card sort literature discusses issues of branding in libraries. ${ }^{6}$ In non-card sorting usability studies, where issues with terminology and nomenclature were important parts of the findings, branding of library resources and services has not been closely examined.

There is little written on branding in academic libraries, whether or not usabil- ity studies played a role. One exception is Duncan and Fichter's case study in which the authors describe the process of naming a new real-time electronic reference service at the Health Sciences Library, University of Saskatchewan. As part of that study, the authors employed a usability technique similar to card sorting called "preference testing" in which test participants selected from among a set of alternative labels or suggested other wording of their choosing. ${ }^{7}$ In this case, preference testing was conducted prior to the introduction of the new service at the University of Saskatchewan. In an article from the professional (nonresearch) literature, Rowley examines branding techniques in libraries and the imperatives that drive them. ${ }^{8}$ In her survey, she linked commercial branding initiatives to what libraries could and already do. For example, she identifies the brand $\log$ as shorthand for everything the brand should mean to users. In the case of libraries, this means display of the library logo on all Web pages where its presence adds to the user experience or understanding.

A couple of key points surfaced in the literature: that "[libraries] already have what every Web site wants: a trusted and respected 'brand' identity [and that they should offer] a highly positive user experience that results in frequent return visits - or what marketers call 'stickiness' to a brand" ${ }^{\prime \prime}$ and that "the choice of cutesy names and logos-sometimes based on the region's mascot or something similar ... may be of possible value for branding and marketing, but of no inherent meaning to new users." 10

\section{Methodology}

In 2005 a new committee was convened at the UIC Library to redesign the library's Web site. In recent years, the Web site had grown to hundreds of pages and sprawled across many subdirectories, partly as a result of decentralized creation and maintenance of the site and pages. The committee was charged with harmo- 
nizing the range of styles evident in the site and ensuring that the pages conform to newly established university visual identity standards, as well as assessing the information content and redesigning the architecture of the site.

As a first step in the UIC Library's Web site redesign project, the committee created a Web survey to gather information regarding the library's Web site such as ease of navigation, quality of content, visual appeal, terminology, most-used features, and frequency of use. The survey was posted on the library's Web site for a month, and three hundred fourteen responses were received. An analysis of the survey results indicated that the two areas that presented the most problems for users were the navigation of the Web site and the terminology used within it. Thus, a subgroup of the committee decided to conduct a card sorting usability test to determine the architecture and terminology of the new library Web site.

Having received approval from the university's Institutional Review Board, the card sort team sent out, in March 2006, an e-mail advertisement for participation in a card sorting test to the participants in the earlier Web survey. In addition, an announcement seeking participants for the card sorting was posted on a campus electronic bulletin board. An incentive of a $\$ 10$ gift card to Barnes \& Noble was offered at the completion of each test, and refreshments were served at the sessions. More than 50 persons expressed interest in participating in the study. In the end, the team scheduled 18 tests and, because of participant dropout, completed 15.

The number and types of participants recruited for the study were based on the recommendations of Jakob Nielsen and adjusted to accommodate the organizational structure of the UIC campus and libraries. ${ }^{11}$ Nielsen states that the five users recommended for traditional usability tests will garner a correlation of only 0.75 in a card sorting usability test, whereas a 0.90 correlation will be achieved by testing 15 users. Tullis and Wood, meanwhile, recommend testing more users, as many as 20 to $30 .{ }^{12}$ However, given limited resources, deadlines for delivering the findings to the Web redesign team, and the marginal gains in correlation that would come from a larger study population (0.93 for 20 participants and 0.95 for $30)$, the researchers decided that testing 15 users would be sufficient.

Participants recruited for card sorting usability studies should be representative of the users of the test site, according to Nielsen, ${ }^{13}$ so the researchers limited participation to the core library users: current students and faculty at UIC. UIC includes two Chicago campuses: one for arts and humanities, social sciences, and professional studies, and another for the health sciences. Additionally, there are health sciences campuses in Peoria, Rockford, and Urbana that are also part of UIC. The library's organization mirrors this structure. Because the two largest site libraries (Chicago's Richard J. Daley Library and Library of the Health Sciences) have comparably sized but otherwise very different user bases, the team drew approximately even numbers of respondents from both those user populations. Graduate students responded in greatest number to the invitation, a result that echoed the library's earlier Web site survey results and may also reflect a higher level of use of and concern for the library's Web presence by that subpopulation. Faculty, meanwhile, responded in modest numbers to the earlier Web survey and almost not at all to the call for card sorting participants, resulting in only one faculty participant in the testing.

Due to logistical considerations, all card sorting sessions were conducted at the Chicago campuses at the participant's choice of either the Richard J. Daley Library or Library of the Health Sciences. Each test participant was given a set of 93 index cards, each one numbered and labeled with the name of a library resource, service, or Web page content either existing or yet-to-be-developed (Appendix A). The 93 labels were pre- 
dominantly drawn from existing links on the library's Web site and augmented by suggestions from the Web site survey. The participants also received a pad of adhesive notes, felt marker, pen, and blank index cards. Using the guidelines developed by the MIT Libraries, ${ }^{14}$ participants were instructed to:

- sort the cards into piles representing categories of information that made sense to them, making as many or as few categories as they chose;

- speak aloud, stating the rationale for sorting cards into the piles created; and

- put a post-it note on top of each pile and write a name for that category on it. The name could be as long and descriptive as the participant chose.

Additionally, the team asked participants to:

- use the blank index cards to create new cards for anything the participant felt was missing or to create duplicate cards where the participant felt that a card belonged in more than one category;

- set aside cards that had no meaning to them in some sort of "discards" pile; and

- make a category called "other" or "general" for cards that seemed not to fit into any category but still should be retained somehow.

Two team members monitored each session, with one providing most of the instructions and both taking notes. Because Nielsen suggests combining correlations with users' comments to inform Web site architecture, ${ }^{15}$ participants were asked to explicate their mental processing of the task at hand while the team members wrote notes on what was said and made other observations. Users were permitted to ask questions during the test, but the monitors could neither define the label on a card nor indicate whether a card referred to existing or potential Web content. Once the sorting was completed, the participant filled out a brief survey about general Internet site usage and preferences. At the end of the session, the team members debriefed the test participants, inviting questions about the card labels, the study, and the library in general.

\section{Findings}

Although the card sort testing was intended to determine the architecture of the library's forthcoming Web site and the language used within it, ${ }^{16}$ the tests inadvertently provided some helpful measure of the efficacy of library branding. A surprising, unanticipated finding was that in no case was the branding widely effective; and, in one case, the brand name was unknown to a majority of the test participants. This has some hard implications for the delivery of library resources and services. ${ }^{17}$

Branding at the UIC University Library is neither comprehensive nor consistent. The library did not actively embark on a unified campaign to brand its resources and services. Instead, the services that were branded were done case by case. Each time a new service was introduced, a name was devised by those who managed it rather than according to a librarywide marketing plan. Among the branded services, there were variant naming conventions and no standard gateways to or other graphic expressions (like watermarks) of the connection between the resource and the library. The branded resources and services all used the initials "UIC" and followed one of two models:

- In apparent emulation of the American Library Association's pervasive “@ your library” campaign, “@UIC" has been appended to the name of the service: MyILL@UIC, ERes@UIC.

- The university's initials have been incorporated directly into names of resources: qUICsearch, InfoqUIC, UICCAT.

Of the 93 cards used in the test, users discarded 47 cards (51\%) at least once. Out of those 47,10 cards were set aside at least 20 percent of the time ( 3 or more instances in the 15 tests). Of the six most discarded cards, five featured some sort of brand- 


\begin{tabular}{|c|c|c|}
\hline \multicolumn{3}{|c|}{$\begin{array}{c}\text { TABLE 1 } \\
\text { Cards Most Frequently Designated } \\
\text { as "Discard," "Unknown," or } \\
\text { "Redundant" }\end{array}$} \\
\hline Card label & Incidence & $\begin{array}{c}\text { Percentage } \\
\%\end{array}$ \\
\hline ERes@UIC & 10 & 67 \\
\hline InfoqUIC & 7 & 47 \\
\hline MyILL@UIC & 6 & 40 \\
\hline qUICsearch & 6 & 40 \\
\hline Resources & 4 & 27 \\
\hline UICCAT & 4 & 27 \\
\hline
\end{tabular}

ing. Leading the way was ERes@UIC, rejected 10 times in the 15 tests, a rate of 67 percent. Table 1 shows how the other branded labels ranked. User recognition varied from one brand to the other. The comments, however, show that even when users recognized the name of the resource and what it stood for, they still found faults with the name.

Of the two “@UIC" styled brands, MyILL@UIC was the better recognized. MyILL@UIC is the library's service that permits interlibrary loan users to place and track requests and view their request history. Five participants (33\%) understood that the "my" part of the name was connected to a personal account and one $(7 \%)$ categorized the card in a manner that connected it to interlibrary loan. The card was otherwise discarded 40 percent of the time, and it remains unknown whether users who categorized the card actually understood what the service is. Two participants $(13 \%)$ referred to this service as "My Illinois at UIC." Although one stated, "My Illinois? I don't know what you mean by this," the other did not indicate what she thought the name meant. The test team speculates that the student may have been thinking of a state government information service or documents repository (the library does have Illinois government documents in its collection) or may have interpreted it as a personal service related to the University of Illinois. Another participant included the card in a pile labeled "portal features," and noted that MyILL@UIC really sounds like a patient history. Whether participants understood the meaning or not, the comments and discard rate demonstrate that the name is not necessarily obvious.

The other brand that used the "@UIC" naming convention was more frequently discarded. ERes@UIC, the library's electronic course reserves service, was discarded 67 percent of the time. Those participants who kept the card did not generally categorize it in a way that suggested understanding of the meaning. In the five tests $(33 \%)$ wherein the card was categorized, two (13\%) had it grouped in "Other" and one each (7\%) in "Searching in General," "Electronic Resources" (which might be logical considering how similarly "resources" and "reserves" may be abbreviated), and "Collections/holdings." In the last instance, the participant (the last to undergo testing) surprised the team by knowing exactly what ERes@UIC was. Although high usage statistics indicate that UIC's electronic reserves service is a success and that students must be familiar with the concept of electronic course reserve readings, the evidence suggests that users have trouble with course reserve terminology in general. In SUNY-Buffalo's card sort test, participants used many names to refer to the service, such as "reserve," "course readings," "class readings," "readings for outside class," and "reading for reserve." 18 Since the service lacks a name that is easily understood by users, branding may not account for the total number of discards. Certainly, though, branding did not make the service more recognizable. One participant thought that ERes@UIC was a page and hold or recall service and another commented that it should fit in with other "acronym-y" names though it did not seem to.

The "acronym-y" names to which the participant referred use the other brand- 
ing convention to integrate the initials "UIC" into brand names at the library. To incorporate the three letters sequentially in a word is challenging. "Quick" is one of the few words in which they appear, and it also describes a desirable characteristic for many services. Consequently, two of the labels play off that word: InfoqUIC and qUICsearch. Test participants did not always connect the idea of "quick" (or "quic") with the names. Several spelled out the "quic" part in pronouncing the names (in other words, $\mathrm{q}-u-i-c$ ), perhaps because it's lacking the final letter "k." Within the library itself, there has been confusion over the spelling of InfoqUIC and qUICsearch. Correct spelling sets off the "UIC" in capitals, but variations have appeared on Web pages, with the whole of "quic" in capitals. Given the inconsistency within the library, that users spelled out the "quic" rather than pronounce it as one syllable was not entirely surprising.

Other than the indications of speediness and institutional branding from the names, users were confronted with "info" and "search," two terms that apply to many things in the library. Users know these words, but they did not always understand them in the context of the service. Some comments and observations:

- One participant thought InfoqUIC might relate to the catalog, saying, "I have no idea what that is."

- One participant thought that InfoqUIC meant "Information Quick" so it should go with "Reference."

- Of qUICsearch, one said, "Must everything be named 'UIC?' ... [Is it] searching libraries? The whole campus? I'll put it by all the searching stuff."

- One participant put qUICsearch with InfoqUIC because of the similar names, pronouncing the latter as InfoQU-I-C instead of as "info-quick" and wondering why the name included the letter "Q."

The two services have very different functions. InfoqUIC is a fee-based article delivery service operated through interlibrary loan and qUICsearch is the library's application of WebFeat's federated catalog and database search tool. These examples demonstrate how unhelpful branded names can be to users.

The third example of the use of "UIC" within the name of a resource is the library's catalog, UICCAT. The term is a contraction of "UIC Catalog" and is similar to catalog names at other academic libraries (for example, AUBIECat at Auburn University and MadCat at the University of Wisconsin-Madison). The pronunciation of UICCAT by library staff is " $u$-i-c-cat," but the team heard several test participants refer to it as "u-cat," which suggests that users might not discern the branding. Indeed, the UIC acronym is ubiquitous around campus. The "CAT" part is not especially well understood either. Users do not necessarily make the link between the three letters and the word "catalog." One participant renamed the card "UICCAT catalog search" and suggested attaching an explanatory note, speculating that non-UIC users will not know what function UICCAT serves. The SUNY-Buffalo study revealed that users grasp the concept of a catalog, but twothirds do not use the term, opting instead for descriptive phrases. ${ }^{19}$ One of the UIC participants likewise asked whether the library might simply rename UICCAT as "find a book" and another participant wondered why the library does not simply name the service or resource for the actual function ("Catalog Search" instead of "UICCAT"). UICCAT as a brand name was not as useful to some test participants as expressions that more explicitly indicate what the actual service or function may be.

The card sort test team did not anticipate any particular, strong, or consistent feedback on the use of the assorted brand names on the library's Web site at the outset of the testing. The branded cards accounted for only 5 of the 93 cards overall (5\%). With such a large number, there were many other possible trends that could have emerged. Moreover, none of the branded resources was especially 
new: each had been in place for more than two years, and one (InfoqUIC) for over ten years. It was striking, then, how many of the participants raised concerns with the branded names.

\section{Conclusions}

Very real concerns about establishing the value of library services to users and to the parent institution drive branding decisions. In times when tight budgets result in careful assessment of the efficacy and efficiency of services, a situation in which users do not know what a service is because of the name is problematic. The UIC Library's card sort usability study revealed several weaknesses in the library's branding efforts that provide guidelines for future branding initiatives:

- Use descriptive language. Use of generic terms and library jargon within brand names is not helpful. For example, "info" (or "information") is so general that it might apply to almost everything at the library. Abbreviating jargon to yield a term like "ERes" (for electronic reserves) further sacrifices clarity for the sake of brevity on the library's Web site. Naming a service with explicit descriptive language that the user will also understand-even if brevity is lost-helps the user identify a library service.

- Use distinct names. Use of the same term ("UIC" in this case) within multiple brand names muddles the distinctions between the various resources and services. Users may think that the resources are related (and so they are, by virtue of the library providing them) when they may not help the user in similar ways at all.

- Provide marketing and instruction for services. Branding alone is not enough. The names of the services at the UIC Library may be confusing to the users, but the team was left wondering whether marketing of the brands would have ameliorated that state. Indeed, it is supposed that some awareness-raising and instruction may always be required in the use of library services and resources.

If efforts other than branding are required, this last point brings up larger questions about why libraries feel it is necessary to communicate their responsibility for services when they have user loyalty and whether there might be a better way to impress this upon users. There are other methods to indicate ownership, mostly visual. Employing standard colors, watermarks, and graphic logos are alternatives that may be effective.

Though card sorting highlighted the limitations of the branding done at UIC, it had several positive outcomes. Participants were very curious about the labels they did not recognize, and the debriefing gave the test team an opportunity to educate them about the library. The feedback was constructive, not simply critical, and the card sort method allowed users to propose terminology that makes sense to them, giving the committee a good start in the Web site redesign. Of course, it was expected that the card sort usability test would inform the architecture and terminology of the UIC Library's new Web site; that it also provided an analysis of branding was a surprise and suggests a new application of such testing for the future. The test results and comments indicate that subjects do use a number of library services and do value the role of libraries on campus.

\section{Notes}

1. Susan Augustine and Courtney Greene, "Discovering how Students Search a Library Web Site: A Usability Case Study," College E Research Libraries 63, no. 4 (July 2002): 354-65.

2. Steve Brantley, Annie Armstrong, and Krystal M. Lewis, "Usability Testing of a Customizable Library Web Portal," College E Research Libraries 67, no. 2 (Mar. 2006): 146-63.

3. Nicole Hennig, "Card Sorting Usability Tests of the MIT Libraries' Web Site: Categories from the User's Point of View," in Usability Assessment of Library-Related Web Sites: Methods and Case Studies, LITA Guide \#7, ed. Nicole Campbell, 88-99 (Chicago: LITA, 2001). 


\section{Using Card Sorting to Evaluate Branding in an Academic Library's Web Site 249}

4. Angi Faiks and Nancy Hyland. "Gaining User Insight: A Case Study Illustrating the Card Sort Technique," College \& Research Libraries 61, no. 4 (July 2000): 349-57.

5. Brenda Battleson and Jane Weintrop, University Libraries Website Nomenclature Test using the Card Sort Method: Summary Report Presented to the University Libraries Web Access Team State University of New York at Buffalo (Spring 2000). Available online from www.jkup.net/BuffaloNomenclatureTest-Spr2000.rtf. [Accessed 3 July 2006].

6. Ruth Dickstein and Vicki Mills, "Usability Testing at the University of Arizona Library: How to Let the Users in on the Design," Information Technology \& Libraries 19, no. 3 (Sept. 2000): 144-51.

7. Vicky Duncan and Darlene M. Fichter, "What Words and Where? Applying Usability Testing Techniques to Name a New Live Reference Service," Journal of the Medical Library Association 92, no. 2 (Apr. 2004): 218-25.

8. Jennifer Rowley, "Online Branding," Online Information Review 28, no. 2 (2004): 131-38.

9. "Building Brand Loyalty: Using Your Library Web Site to Promote Return Visits. Suggestions made by John Lubans at the 2000 Illinois Library Association Conference," Illinois Library Association Reporter 18, no. 6 (Dec. 2000): 7-8.

10. "Naming Conventions," LISWiki. Available online from http://liswiki.org/wiki/Naming_conventions. [Accessed 5 July 2006].

11. Jakob Nielsen, "Card Sorting: How Many Users to Test," Alertbox: Current Issues in Web Usability, July 19, 2004. Available online from www.useit.com/alertbox/20040719.html. [Accessed 22 November 2006].

12. Tom Tullis and Larry Wood, "How Many Users Are Enough for a Card-Sorting Study?" Paper, Usability Professionals Association (UPA) 2004 Conference, Minneapolis, Minn., June 7-11, 2004. Available online from http://home.comcast.net/\%7Etomtullis/publications/ UPA2004CardSorting.pdf. [Accessed 22 November 2006].

13. Nielsen, "Card Sorting: How Many Users to Test."

14. Hennig, "Card Sorting Usability Tests of the MIT Libraries' Web Site," 91-92.

15. Nielsen, "Card Sorting: How Many Users to Test."

16. A full analysis of the card sort results will be published by the authors in a separate, forthcoming paper.

17. The authors have chosen "resources and services" to refer to the branded items while recognizing the vagueness of the terminology. One card sort participant noted that everything in the library is a resource. The discard results in table 1, meanwhile, demonstrate the meaninglessness of that label. MIT and SUNY-Buffalo also found that participants didn't recognize the terms "resource" or "electronic resource."

18. Battleson and Weintrop, University Libraries Website Nomenclature Test using the Card Sort Method, 2. The authors do not indicate whether "course reserves" are electronic or physical in format.

19. Ibid. 


\section{APPENDIX A \\ Card Sort Labels}

1 access to other libraries

2 alerts

3 articles

4 ask a librarian

5 audio/visual equipment

6 audio/visual materials

$7 \quad a-z$ list of article databases

8 a-zlist of electronicjournals, newspapers, and magazines

9 books

10 calendar

11 catalog search

12 circulation policies

13 citation style guides

14 comments and suggestions

15 contact the library

16 copyright policies and procedures

17 course reserves

18 digital collections

19 disability services

20 document delivery

21 electronic journals, newspapers, and magazines

22

45 Library of the Health Sciences-Chicago

46 Library of the Health Sciences-Peoria

47 Library of the Health Sciences- Rockford
48 Library of the Health Sciences-Urbana

49 locations and addresses

50 maps collection

51 microfilm/microfiche

52 mission statement

53 my account

54 MyILL@UIC

55 National Network of Medical Libraries

\section{Greater Midwest Region}

56 new books

57 off-campus access to library databases

58 online tutorials for research

59 other library catalogs

60 page and hold materials

61 patents and patent information

62 PDAs

63 phone numbers

64 photocopying

65 photography collections

66 qUICsearch

67 rare books \& manuscripts

68 reference books

69 reference desk hours

70 refworks (citation management)

71 renew books

72 request materials from another library

73 research assistance

74 research consultation

75 resources

76 Richard J. Daley Library

77 scanning and photographic services

78 Science Library

79 search the Web site

80 services

81 site map

82 special collections

83 staff directory

84 study rooms

85 subject guides

86 subject list of article databases

87 subject list of electronic journals, newspapers, and magazines

88 suggest a purchase

89 tours \& orientation

90 UICCAT

91 university archives

92 virtual tour of the library

93 wireless access 


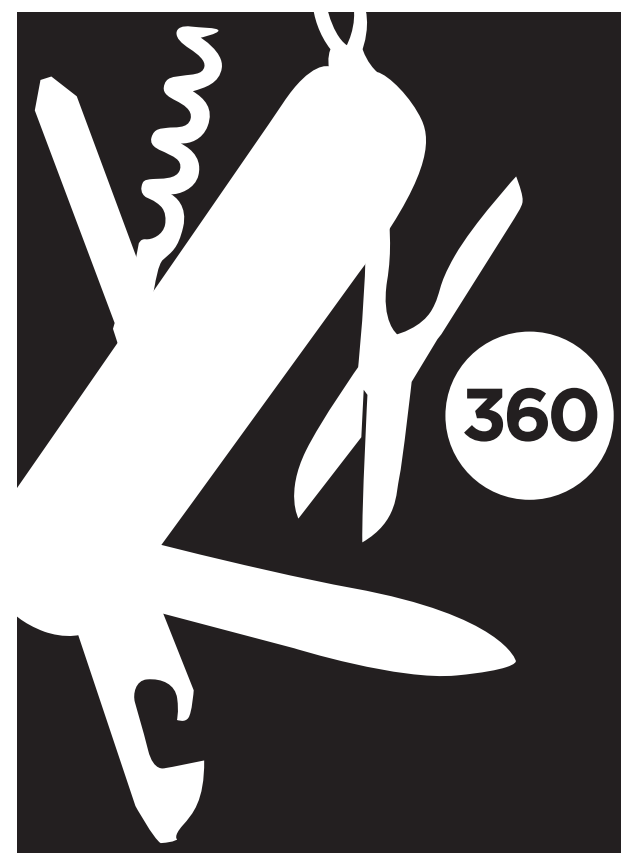

Counter

assessment tools make it easy to optimize the value of e-resources

- Compare results between different providers

- Generate customized reports

- Share report with stakeholders

- Make more informed acquisition decisions

- Optimize usage and value of your electronic collection

- Archive results for historical perspective

SERIALS SOLUTIONS

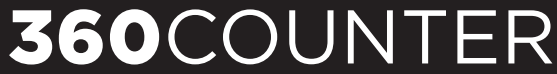

Helping your library make better decisions

SerialsSolutions 